\title{
Aproveitamento de cinzas de caroços de pêssego como substrato da construção civil
}

\section{Caroline da Silva Rodrigues ${ }^{1}$, Ricardo Lemos Sainz ${ }^{2}$,* e Mateus Berwaldt Santos ${ }^{2}$}

${ }^{1}$ Instituto Federal Sul Rio-Grandense. Curso de Pós-Graduação em Engenharia e Ciências Ambientais. Campus Pelotas. Praça Vinte de Setembro, 455. Centro. Pelotas-RS, Brasil (CEP 96015-360).

${ }^{2}$ Instituto Federal Sul-Rio-Grandense. Campus Pelotas. Praça Vinte de Setembro, 455. Centro. Pelotas-RS, Brasil (CEP 96015-360). *E-mail: ricardosainz@pelotas.ifsul.edu.br.

Resumo. A cultura de pêssego no Brasil data do século XVI quando chegou ao País, sendo o Estado do Rio Grande do Sul responsável por expressiva produção, aproximadamente 160 mil toneladas/ano, onde a região de Pelotas representa $90 \%$ desta produção, demostrando relevante a questão do descarte dos resíduos gerados nesta cadeia produtiva, especialmente o caroço, que atualmente não possui uma destinação adequada e gera problemas ambientais devido ao descarte irregular. Como forma de minimizar o problema, uma das alternativas é o emprego dos caroços de pêssego para obtenção de energia nas caldeiras das próprias indústrias, porém esta prática gera outro passivo ambiental que são as cinzas dos caroços de pêssego. Este trabalho objetiva verificar a possibilidade da aplicação das cinzas de caroços de pêssego como substrato para construção civil. A cinza foi utilizada em substituição parcial de outros componentes do traço de assentamento. No tratamento preliminar se substituiu $30 \%$ de cada componente do traço (cimento: cal: areia) constatou-se que a substituição da areia pela cinza apresentou o melhor resultado. Na segunda bateria de ensaios substituiu-se $20 \%, 30 \%$ e $40 \%$ da cal pela cinza, obtendo-se este último o melhor resultado validando a hipótese do estudo. Sendo assim a substituição é viável, útil e possível, onde há o aumento de resistência da mesma, inclusive sendo superior aos padrões estabelecidos pela ABNT NBR 13279/2005.

Palavras-chave: Aproveitamento de resíduos; Caroços de pêssego; Construção civil.

Abstract. Utilization of peach stone ashes as a substrate for civil construction. The peach culture in Brazil dates back to the 16th century when it arrived in the country. The State of Rio Grande do Sul, Brazil, is responsible for a significant production, approximately 160 thousand tons/year, where the Pelotas Region represents $90 \%$ of this production, it is relevant to discard the
Recebido

$18 / 05 / 2020$

Aceito

$29 / 08 / 2020$

Publicado

$31 / 08 / 2020$

Acesso aberto

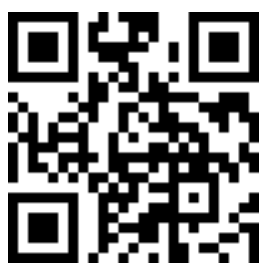

ORCID

(D) 0000-0003-4765-9796

Caroline da Silva

Rodrigues

() 0000-0001-9338-7993

Ricardo Lemos Sainz

D 0000-0002-0149-0350

Mateus Berwaldt

Santos

ISSN 2359-1412/RBGAS-2020-00077/2020/7/16/36/1031

Rev. Bras. Gest. Amb. Sustent.

http://revista.ecogestaobrasil.net 
waste generated in this production chain, especially the stone, which currently does not have an adequate destination and generates environmental problems due to irregular disposal. As a way to minimize the problem, one of the alternatives is the use of the peach cores to obtain energy in the boilers of the industries themselves. This practice generates another environmental liability that is the ashes of peach kernels. This work aims to verify the possibility of the application of these ashes as substrate for civil construction, where it was used in partial substitution of other components of the settlement trace. In the preliminary treatment, $30 \%$ of each component of the trace (cement: lime : sand) was replaced, replacing the sand with the ash showed the best result. In the second battery of tests, $20 \%$, $30 \%$ and $40 \%$ of the lime were replaced by ash, obtaining as a best result the $40 \%$ treatment, validating the hypothesis of the study, being substitution feasible, useful and possible, where we verified the increase of resistance of it, including being higher than the standards established by ABNT NBR 13279/2005.

Keywords: Waste utilization; Peach stones; Civil construction.

\section{Introdução}

O pêssego chegou ao Brasil no século XVI, trazido pelos portugueses, originário da China, adaptou-se ao clima temperado da região, encontrando nos estados do sul do país, as melhores condições para sua expansão (Fachinello, 2004).

Na década de 1960 já estava consolidada a exploração de pomares de pessegueiros no Rio Grande do Sul, representando mais de $50 \%$ da produção nacional. Nas safras de 2002 a 2006 o Rio Grande do Sul atinge o marco de 67\% da área colhida de pessegueiros no Brasil. A produção de base familiar representa $90 \%$ dos pomares do País, sendo mais significativa a parcela de produtores no Sul do Brasil (Madail e Raseira, 2008).

Neste cenário o estado do Rio Grande do Sul produz aproximadamente 160 mil toneladas/ano e a Região de Pelotas representa 90\% desta produção, além de ser referência na produção de pêssegos em conserva (EMATER, 2014).

Deste modo, Pelotas e região produzem $100 \%$ do pêssego em calda brasileiro (Heylmann, 2015) e sob este cenário, são produzidas cerca de 50 milhões de latas de pêssegos em calda por ano, gerando anualmente cerca de 1.000 toneladas de caroços.

Segundo Oliveira (2008), durante o processo produtivo, as agroindústrias acabam por gerar significativa quantidade de resíduo de caroços de pêssegos, onde o destino de tais resíduos muitas vezes se dá com a prática da disposição direta em aterro sanitário, em desconformidade com legislação vigente, desencadeando uma série de problemas ambientais, sugerindo assim o aproveitamento de resíduos para obtenção de carvão ativado a partir dos caroços de pêssegos da região.

Outra solução bastante aplicada e, extremamente viável, é a utilização dos caroços de pêssegos para produção de energia. É possível queimar os caroços diretamente em caldeiras industriais sem a necessidade de grandes adaptações do equipamento. Prática esta que permite minimizar o volume de dejetos a serem lançados na natureza e também tornar mais eficiente o ciclo produtivo da indústria, diminuindo seus custos de geração de energia. 
Segundo Diniz et al. (2004) o caroço de pêssego tem um alto potencial de geração calorífica, gerando cerca de $3400 \mathrm{cal} \mathrm{g}^{-1}$, o que o torna bastante interessante sua queima na própria indústria, minimizando custos diretos e, obviamente, custos ambientais, o que acaba gerando as cinza, como resíduo final. 0 caroço de pêssego gera cerca de 3,8\% de sua massa em cinzas, acarretando somente na Região de Pelotas, 38 toneladas de resíduos anuais.

Portanto, é interessante em termos ambientais a busca de alternativas ao simples despejo destes dejetos no meio ambiente. Uma delas pode ser a utilização das cinzas provenientes da queima dos caroços de pêssegos como substrato da construção civil, o que seria um destino ambientalmente correto e economicamente viável ao resíduo. A viabilização desta aplicação poderia aproximar a cadeia produtiva agroindustrial do pêssego da chamada metodologia ZERI (Zero Emission Reserach Iniciative) (Hueblin, 2001).

Os impactos ambientais provenientes da construção civil são expressivos, e por isso motivo de preocupação para pesquisadores, ambientalista, e empresários. Dentro dos materiais fabricados e utilizados em larga escala na construção civil, destacam-se os blocos de cerâmica e de concreto, que utilizam significativa quantidade de recursos naturais extraídos de energia despendida (Conte, 2014).

Segundo Conte (2014) a preocupação atual referente ao aproveitamento de resíduos industriais, vem ganhando força, devido aos impactos ambientais envolvendo a destinação final destes resíduos. No Rio Grande do Sul, dentre os resíduos industriais, destacam-se as cinzas oriundas da queima do carvão mineral, tais cinzas são divididas basicamente entre leves e pesadas, sendo que as leves ou voláteis são utilizadas na indústria cimenteira, já as pesadas não possuem destinação comercial.

Com estes dados, Conte (2014) propõe um destino mais adequado para o resíduo, desenvolvendo estudo para geração de blocos para alvenaria, caracterizados por apresentar em sua composição, cinzas pesadas de carvão mineral, e apresenta resultados satisfatórios mediante experimento executado obedecendo às normas de desempenho estabelecidas pelas Normas Regulamentadoras Brasileiras (NBR), da Associação Brasileira de Normas Técnicas (ABNT).

Em estudo semelhante Tashima et al. (2011) utilizando a cinza da casca de arroz na construção civil, observaram que a substituição de $15 \%$ e $25 \%$ de cimento por cinza de casca de arroz apresentou melhores resultados referente à resistência aos 91 dias, em relação ao concreto de referência (sem adição do mineral).

Considerando o cenário atual, verifica-se que o caroço do pêssego é um passivo ambiental produzido em larga escala nas indústrias sem destinação correta, e somente uma pequena alíquota deste resíduo que possui grande potencial energético, é utilizado em caldeiras substituindo a lenha, mesmo sendo esta uma solução viável tanto ambiental como economicamente, porém existem (Diário Popular, 2015a, 2015b). Porém deste processo surge um novo passivo ambiental, a cinza, que não possui uma destinação adequada, então se minimiza problema ambiental do caroço e surge a questão da melhor destinação da cinza.

O objetivo deste trabalho foi estudar a viabilidade da utilização da cinza do caroço de pêssego como substituinte de um ou mais componentes no traço da argamassa de assentamento para alvenaria na construção civil, barateando o custo da construção sem comprometer a resistência exigida nas normas técnicas. Verificando a eficiência do emprego da cinza do caroço de pêssego na composição da argamassa de assentamento, como alternativa de destinação adequada dos resíduos da cadeia agroindustrial do pêssego. 


\section{Materiais e métodos}

\section{Matéria-prima}

Para obtenção da cinza foram utilizados caroços de pêssego da safra de 2015-2016 que se encontravam na plataforma de concreto, já secos, disponibilizados pela indústria de Conservas Albino Neumann \& Cia Ltda. Os caroços foram coletados e armazenados em sacos de estopa até sua utilização. Os ensaios realizados nas dependências do Campus Pelotas do Instituto Federal Sul-Rio-Grandense (IFSUL).

Obtenção da cinza. Os caroços foram expostos à queima controlada em forno Cubilot, em temperatura de aproximadamente $450^{\circ} \mathrm{C}$, no laboratório de fundição do Curso de Mecânica do Campus Pelotas do IFSUL.

Ensaio de granulometria. Foi realizado nos laboratórios de Mecânica dos solos, do Curso de Edificações - Campus Pelotas- IFSUL, logo após a queima do caroço, (tanto da areia como da cinza do caroço de pêssego) conforme a NBR 7217/1987 (ABNT, 1987).

Estudo preliminar - Elaboração do traço da argamassa de assentamento

Em primeiro momento realizou-se os ensaios com base no traço 1:2:9 (cimento : cal : areia) para argamassas de assentamento, seguindo as indicações da NBR 13276/2002 (ABNT, 2002), foi realizada a substituição de 30\% dos 3 (três) elementos que constituem a argamassa, pela cinza obtida na queima dos caroços, e um traço convencional ao qual nos referimos por referência, onde se seguiu o traço sem alteração, baseado em estudos semelhantes já realizados, como o de Tashima et al. (2011),

Estudo Final - Elaboração do traço da argamassa de assentamento com substituição parcial da cal por cinza

Substituiu-se nos corpos de prova $20 \%, 30 \%$ e $40 \%$ da cal pela cinza, para o traço referência 1:1:6, objetivando observar a resistência dos diferentes tratamentos (corpos de prova) aos padrões exigidos pela NBR 13279/2005, onde o exigido é 1,5 MPa para argamassa de assentamento para fim de vedação e 4,5 Mpa para argamassa de assentamento para fins estruturais, visto que não se atingiu os valores no traço anterior (1:2:9), além de um melhor controle na relação água/cimento $(\mathrm{a} / \mathrm{c})$.

\section{Ensaio de Índice de Consistência}

Logo após a mistura dos componentes da argamassa, se realizou o ensaio de consistência conforme NBR 13276/2002 (ABNT, 2002) a fim de verificar sua trabalhabilidade.

\section{Moldagem, desforma e imersão}

Os corpos de prova foram moldados seguindo a NBR 13276/2002 (ABNT, 2002) e NBR 13279/2005 (ABNT, 2005), na quantidade de 12 corpos de prova para cada traço (três traços por idade). Após a preparação dos traços e moldagem se aguardou $24 \mathrm{~h}$ para desforma, nos dois primeiros traços, e nos demais se aguardou 48h para evitar danos nos corpos de prova, submetendo os corpos de provas à imersão em água com cal para cura, que tem como finalidade evitar fissuras devido à retração, ou seja, a redução do volume da argamassa devido à perda de água. A cal corrige o $\mathrm{pH}$ da água durante o processo de endurecimento da argamassa, o que facilita a hidratação do cimento e torna mais rápido o ganho de resistência.

\section{Ensaios de compressão}

O ensaio de compressão foi realizado de acordo com a NBR 13279/2005 (ABNT, 2002), no Laboratório de Materiais de Construção, no Curso de Edificações, após 7, 14, 21 e 28 dias em cura por imersão, se retirou os corpos de provas das idades correspondentes $24 \mathrm{~h}$ para os traços 1 e 2 e $48 \mathrm{~h}$ para os demais, antes da data de rompimento e se submeteu ao equipamento de compressão (conjunto de medidas tomadas para manter a umidade da argamassa durante o endurecimento permitindo a hidratação do cimento), seguindo a NBR 13279/2005 (ABNT, 2005): 


\section{Resultados e discussão}

Nos ensaios granulométricos o material foi separado nas peneiras conforme sua granulometria como pode ser observado na Tabela 1.

Tabela 1. Resultados de ensaio granulométrico realizado no Laboratório de Mecânica dos Solos, do Curso Técnico em Edificações, utilizando-se $1 \mathrm{~kg}$ de areia e $1 \mathrm{~kg}$ de cinza.

\begin{tabular}{|l|c|c|c|}
\hline \multirow{2}{*}{ Peneira (mm) } & \multicolumn{3}{|c|}{ Material retido (g) } \\
\cline { 2 - 4 } & Cinza & Areia úmida & Areia seca \\
\hline 76 & 0 & 0 & 0 \\
\hline 38 & 0 & 0 & 0 \\
\hline 19 & 0 & 0 & 0 \\
\hline 9,5 & 78,6 & 0 & 4,0 \\
\hline 4,8 & 134,2 & 4,0 & 33,3 \\
\hline 2,4 & 100,2 & 33,40 & 148,7 \\
\hline 1,2 & 100,1 & 149,3 & 298,3 \\
\hline 0,6 & 135,2 & 299,5 & 357,3 \\
\hline 0,3 & 164,7 & 358,7 & 128,6 \\
\hline 0,15 & 171,1 & 129,1 & 26,4 \\
\hline Fundo & 117,4 & 26,5 & \\
\hline
\end{tabular}

Estes resultados indicam a diferença granulométrica presente na massa de cinza e areia. Na preparação do traço por questões de granulometria usaram-se as cinzas contidas nas peneiras $0,3 \mathrm{~mm}-0,15 \mathrm{~mm}$ e fundo, visto a granulometria mais semelhante à cal, onde a NBR 7175/2003 (ABNT, 2003) estabelece que no máximo 0,5\% da cal utilizada no ensaio de granulometria pode ficar retida na peneira de abertura 0,6 $\mathrm{mm}$. Como este trabalho propõe a substituição de parte da cal por cinza, então a cinza utilizada foi a passante na peneira $0,6 \mathrm{~mm}$, e toda a areia contida nas peneiras utilizadas no ensaio de granulometria foi utilizada na preparação da argamassa.

Já com o melhor resultado das três substituições (cimento: cal: areia), decidiu-se modificar o traço, que anteriormente era 1:2:9 para 1:1:6 (cimento : cal : areia), para obter uma melhor resistência. Foi decidido realizar a substituição da cal pela cinza, e manter as quantidades dos demais componentes da argamassa.

Obtendo os resultados mostrados nas Tabelas 2 e 3.

Tabela 2. Resultados do Ensaio de Índice de Consistência, em ensaio realizado em 08 e $13 / 07 / 2017$.

\begin{tabular}{|c|c|c|c|}
\hline $\begin{array}{c}\text { Traço1 } \\
\text { Substituição de 30\% } \\
\text { do cimento }\end{array}$ & $\begin{array}{c}\text { Traço 2 } \\
\text { Substituição de 30\% } \\
\text { da cal }\end{array}$ & $\begin{array}{c}\text { Traço 3 } \\
\text { Substituição de 30\% } \\
\text { da areia }\end{array}$ & $\begin{array}{c}\text { Traço 4 } \\
\text { Traço referência - } \\
\text { Branco }\end{array}$ \\
\hline $158,90 \mathrm{~mm}$ & $184,86 \mathrm{~mm}$ & $251,00 \mathrm{~mm}$ & $223,90 \mathrm{~mm}$ \\
\hline
\end{tabular}

Tabela 3. Resultados do Ensaio de Índice de Consistência, em ensaio realizado em 13 e 20/09/2017.

\begin{tabular}{|c|c|c|c|}
\hline $\begin{array}{c}\text { Traço 5 } \\
\text { Substituição de 20\% } \\
\text { da cal }\end{array}$ & $\begin{array}{c}\text { Traço 6 } \\
\text { Substituição de } \mathbf{3 0 \%} \\
\text { da cal }\end{array}$ & $\begin{array}{c}\text { Traço 7 } \\
\text { Substituição de 40\% } \\
\text { da cal }\end{array}$ & $\begin{array}{c}\text { Traço 8 } \\
\text { Traço referência - } \\
\text { Branco }\end{array}$ \\
\hline $207,00 \mathrm{~mm}$ & $191,67 \mathrm{~mm}$ & $195,00 \mathrm{~mm}$ & $207,00 \mathrm{~mm}$ \\
\hline
\end{tabular}


Na NBR 13276/2002 (ABNT, 2002) não consta qual o resultado esperado nos ensaios de índice de consistência, porém em referências bibliográficas observa-se a recomendação é de $250 \mathrm{~mm}$, podemos verificar que embora não esteja enquadrado dentro do valor referido, as medias obtidas no ensaio não estão distantes do exigido, visto que se utilizou a relação água/cimento (a/c) de 1,20 e para não comprometer a resistência dos corpos e provas se optou por manter o fator a/c e não adicionar mais água para chegar ao valor referenciado de $250 \mathrm{~mm}$.

Os resultados obtidos nos ensaios de compressão são divididos em dois momentos, o primeiro onde se buscou o melhor resultado na utilização da cinza pela substituição de cimento, cal e areia; e em segundo momento, para verificar qual a melhor porcentagem de substituição de cinza pela cal. Alguns corpos de provas foram danificados na desforma e por este motivo não há valores nas tabelas pois não foram utilizados nos ensaios (Tabelas 4 e 5).

Tabela 4. Ensaio de compressão - argamassa com cinza de caroço de pêssego. Traço 1:2:9.

\begin{tabular}{|l|c|c|c|c|}
\hline Tempo de cura & $\begin{array}{c}\text { Traço 1* } \\
\text { Mpa }\end{array}$ & $\begin{array}{c}\text { Traço 2* } \\
\text { Mpa }\end{array}$ & $\begin{array}{c}\text { Traço 3* } \\
\text { Mpa }\end{array}$ & $\begin{array}{c}\text { Traço 4* } \\
\text { Mpa }\end{array}$ \\
\hline 7 dias & & & & \\
\hline C.P 1 & $0,30^{\mathrm{a}}$ & $0,63^{\mathrm{c}}$ & $0,79^{\mathrm{c}}$ & $0,69^{\mathrm{c}}$ \\
\hline C.P 2 & $0,35^{\mathrm{a}}$ & $0,69^{\mathrm{c}}$ & $0,63^{\mathrm{c}}$ & $0,57^{\mathrm{c}}$ \\
\hline C.P 3 & - & - & $0,77^{\mathrm{b}}$ & $0,63^{\mathrm{c}}$ \\
\hline 14 dias & & & & \\
\hline C.P 1 & $0,42^{\mathrm{b}}$ & $1,15^{\mathrm{f}}$ & $0,88^{\mathrm{d}}$ & $0,72^{\mathrm{d}}$ \\
\hline C.P 2 & $0,40^{\mathrm{a}}$ & $0,87^{\mathrm{d}}$ & $0,99^{\mathrm{e}}$ & $0,94^{\mathrm{d}}$ \\
\hline C.P 3 & $0,47^{\mathrm{b}}$ & $1,01^{\mathrm{e}}$ & $0,75^{\mathrm{d}}$ & $0,77^{\mathrm{c}}$ \\
\hline 21 dias & & & & \\
\hline C.P 1 & $0,51^{\mathrm{b}}$ & $1,22^{\mathrm{f}}$ & $1,29^{\mathrm{f}}$ & $0,97^{\mathrm{e}}$ \\
\hline C.P 2 & $0,49^{\mathrm{b}}$ & $0,96^{\mathrm{d}}$ & $1,22^{\mathrm{f}}$ & $0,87^{\mathrm{d}}$ \\
\hline C.P 3 & - & $0,95^{\mathrm{d}}$ & $1,16^{\mathrm{f}}$ & - \\
\hline 28 dias & & & & \\
\hline C.P 1 & $0,39^{\mathrm{a}}$ & $1,23^{\mathrm{f}}$ & $1,43^{\mathrm{g}}$ & $1,14^{\mathrm{f}}$ \\
\hline C.P 2 & $0,42^{\mathrm{b}}$ & $1,25^{\mathrm{f}}$ & $1,31^{\mathrm{g}}$ & $0,99^{\mathrm{e}}$ \\
\hline C.P 3 & $0,57^{\mathrm{c}}$ & $1,23^{\mathrm{f}}$ & $1,31^{\mathrm{g}}$ & $0,80^{\mathrm{c}}$ \\
\hline
\end{tabular}

Legenda: Traço 1 - Substituição de 30\% do cimento por cinza; Traço 2 - Substituição de 30\% da cal por cinza; Traço 3 - Substituição de 30\% da areia por cinza; Traço 4 - Referência/Branco. ( ${ }^{*}$ ) Índices iguais indicam que não há variação significativa dos valores considerando o Teste de Tukey a $5 \%$ de probabilidade.

Observa-se que o traço 3 apresentou melhor resultado referente à resistência após os 28 dias de cura.

Na primeira bateria de ensaios se constatou que a substituição da cinza obteve uma melhor resistência respectivamente na substituição de parte de areia, sendo o resultado superior até mesmo ao traço original/referência, porém a diferença de resistência entre a substituição de areia e cal não diferiu significativamente, por uma questão de uma afinidade química da cal com a cinza se optou por substituir a cal, visto a expectativas de melhores resultados, já que no ensaio final mudou-se o traço. Podemos observar esta diferença na Figura 1. 


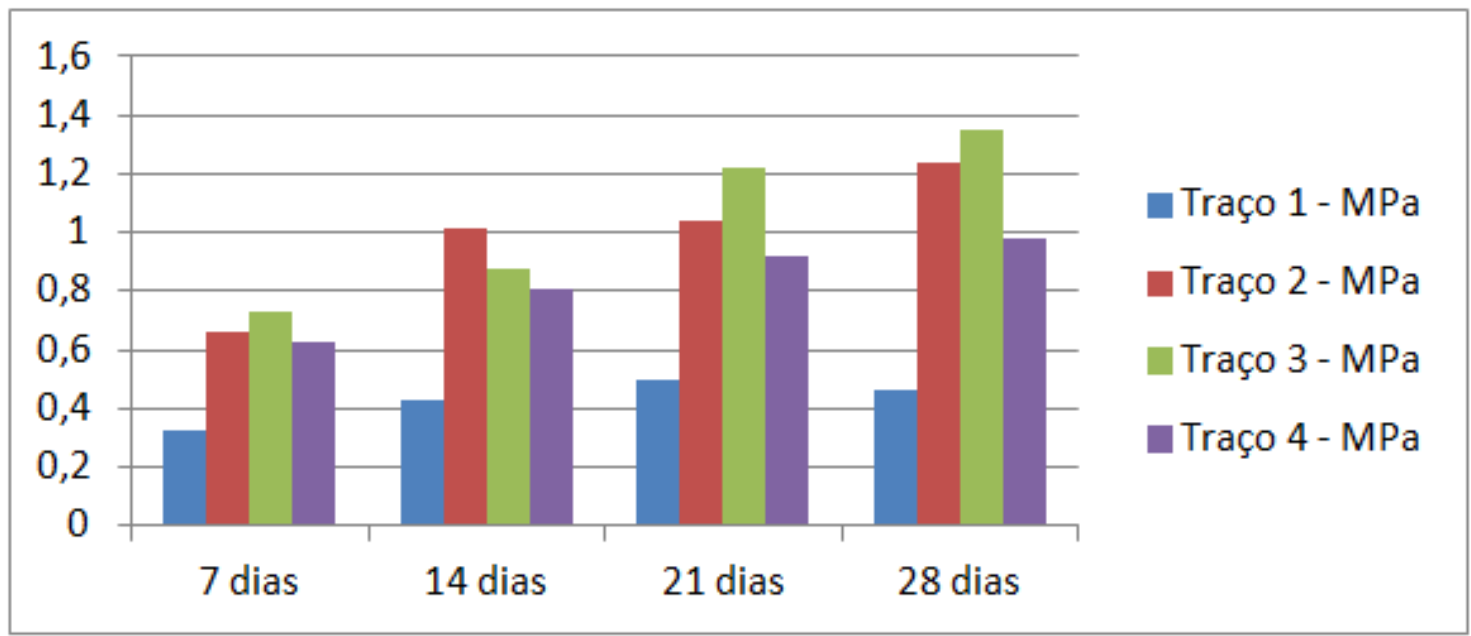

Figura 1. Resultados do ensaio preliminar de compressão, em MPa. Traço 1 - Substituição de 30\% do cimento por cinza; Traço 2 - Substituição de 30\% da cal por cinza; Traço 3 - Substituição de 30\% da areia por cinza; Traço 4 - Referência/Branco.

Na Figura 1 os valores de tensão apresentados são as médias para cada idade, sendo que os valores fora do desvio padrão foram excluídos do cálculo da média.

Na segunda bateria de ensaios substituiu-se $20 \%, 30 \%$ e $40 \%$ da cal pela cinza, como se pode observar nos dados contidos na Tabela 5.

Tabela 5. Ensaio de compressão - argamassa com cinza de caroço de pêssego, Traço 1:1:6.

\begin{tabular}{|c|c|c|c|c|}
\hline Tempo de Cura & $\begin{array}{c}\text { Traço 5* } \\
\text { Mpa }\end{array}$ & $\begin{array}{c}\text { Traço 6* } \\
\text { Mpa }\end{array}$ & $\begin{array}{c}\text { Traço } 7 \\
\text { Мpa }\end{array}$ & $\begin{array}{c}\text { Traço } 8 \\
\text { Мpa }\end{array}$ \\
\hline \multicolumn{5}{|l|}{7 dias } \\
\hline C.P 1 & $2,17^{\mathrm{a}}$ & $2,62^{b}$ & $3,55^{c}$ & $2,86^{\mathrm{b}}$ \\
\hline C.P 2 & $3,34^{c}$ & $2,86^{b}$ & $3,56^{c}$ & $3,27^{c}$ \\
\hline C.P 3 & $2,67^{b}$ & $2,81^{b}$ & $3,54^{c}$ & $2,74^{b}$ \\
\hline \multicolumn{5}{|l|}{14 dias } \\
\hline C.P 1 & $3,65^{d}$ & $3,94^{\mathrm{e}}$ & $4,70^{\mathrm{e}}$ & $4,11^{d}$ \\
\hline C.P 2 & $3,48^{c}$ & $3,76^{d}$ & $4,31^{d}$ & $3,52^{\mathrm{c}}$ \\
\hline C.P 3 & $3,83^{\mathrm{d}}$ & $3,26^{c}$ & $4,61^{\mathrm{d}}$ & $4,52^{d}$ \\
\hline \multicolumn{5}{|l|}{21 dias } \\
\hline C.P 1 & $4,68^{\mathrm{e}}$ & $5,04^{\mathrm{f}}$ & $6,11^{g}$ & $5,41^{f}$ \\
\hline C.P 2 & $4,93^{f}$ & $4,84^{f}$ & $6,16^{g}$ & $3,71^{c}$ \\
\hline C.P 3 & $4,96^{f}$ & $4,53^{f}$ & $6,36^{\mathrm{h}}$ & $5,12^{\mathrm{f}}$ \\
\hline \multicolumn{5}{|l|}{28 dias } \\
\hline C.P 1 & $5,90 \mathrm{~g}$ & $6,11 \mathrm{~g}$ & $7,18^{i}$ & $5,65 \mathrm{~g}$ \\
\hline C.P 2 & $5,90 \mathrm{~g}$ & $5,14^{\mathrm{f}}$ & $7,23^{i}$ & $7,28^{\mathrm{i}}$ \\
\hline C.P 3 & $6,52^{\mathrm{h}}$ & $5,70^{\mathrm{f}}$ & $5,85 \mathrm{~g}$ & $6,06^{g}$ \\
\hline
\end{tabular}

Legenda: Traço 5 - Substituição de 20\% da cal por cinza; Traço 6 - Substituição de 30\% da cal por cinza; Traço 7 - Substituição de 40\% da cal por cinza; Traço 8 - Referência/Branco. (*) Índices iguais indicam que não há variação significativa dos valores considerando o Teste de Tukey à $5 \%$ de probabilidade. 
Analisando estes dados, constatou que a melhor substituição foi a de $40 \%$, onde se obteve uma melhor resistência, que se enquadra dentro dos padrões estabelecidos pela NBR 13279/2002 (ABNT, 2002), sendo superior ao exigido, podendo esta argamassa de assentamento ser utilizada tanto para fins de vedação como para fins estruturais (Figura 2).

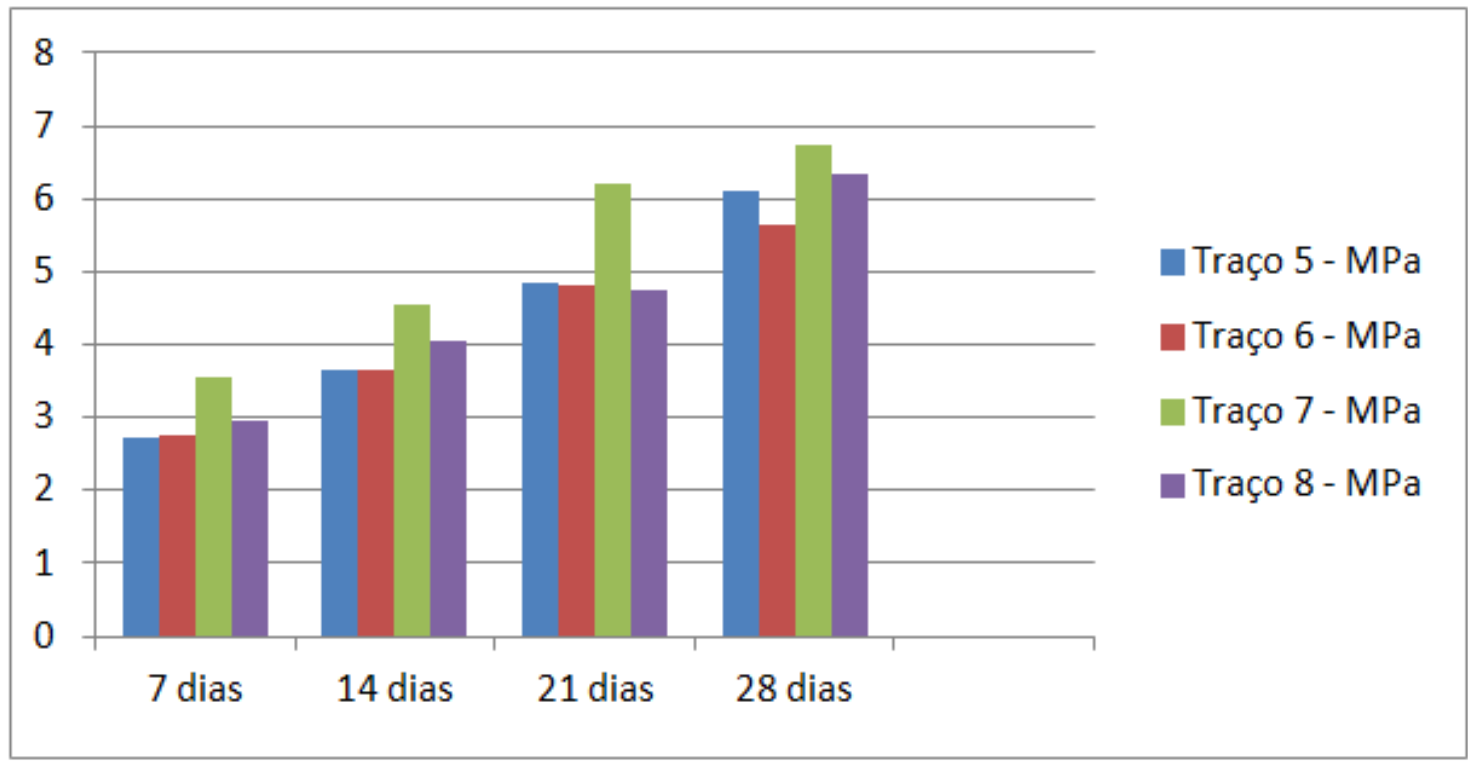

Figura 2. Resultados do ensaio final de compressão. Legenda: Traço 5 - Substituição de $20 \%$ da cal por cinza; Traço 6 - Substituição de 30\% da cal por cinza; Traço 7 - Substituição de 40\% da cal por cinza; Traço 8 - Referência/Branco.

\section{Conclusão}

A utilização da cinza de caroços de pêssego para obtenção de argamassa de assentamento na construção civil se mostra uma possibilidade viável, útil e possível, pois ao analisar os resultados dos ensaios de compressão constata-se que a substituição de $40 \%$ da cal pela cinza, apresentou maior aumento de resistência da argamassa, inclusive sendo superior ao exigido pela norma vigente. 0 uso da cinza não provocou mudanças significativas no índice de consistência e, portanto, na trabalhabilidade. Evidencia-se o aumento da resistência do produto final e o beneficio ambiental na aplicação do material para este fim.

\section{Conflito de interesses}

Os autores declaram não haver conflito de interesses.

\section{Referências}

ABNT - Associação Brasileira de Normas Técnicas. ABNT NBR 7217:1987 - Agregados Determinação da composição granulométrica. Rio de Janeiro: ABNT, 1987. 
ABNT - Associação Brasileira de Normas Técnicas. ABNT NBR 13276:2002 - Argamassa para assentamento e revestimento de paredes e tetos - Preparo e índice de consistência. Rio de Janeiro: ABNT, 2002.

ABNT - Associação Brasileira de Normas Técnicas. ABNT NBR 13279:2005 - Argamassa de paredes e tetos - Determinação da resistência à tração na flexão e á compressão. Rio de Janeiro: ABNT, 2005.

AZONASUL - Associação dos Municípios da Zona Sul. Dados da cadeia produtiva do pêssego. Disponível em: <http://www.azonasul.org.br/Noticia/1520/DADOS-CADEIAPRODUTIVA-DO-PESSEGO>. Acesso em: 18 jul. 2016.

Conte, R. L. Alvenaria com blocos à base de cinzas pesadas da queima do carvão mineral: análise de desempenho. Porto Alegre: Universidade Federal do Rio Grande do Sul, 2014. (Trabalho de conclusão de curso).

Diário Popular. Estudo mostra que caroço do pêssego pode ter mil e uma utilidades. Diário Popular, Pelotas, 25 de janeiro de 2015a. p.2. Disponível em: $<$ http://www.diariopopular.com.br/tudo/index.php?n_sistema=3056\&id_noticia=0TUwM Dc=\&id_area=NQ>. Acesso em: 18 jul. 2019.

Diário Popular. Um destino nobre ao caroço de pêssego. Diário Popular, Pelotas, 25 de janeiro de 2015b. p. 2. Disponível em: <http://www.bioquim.com.br/htmlarea/ midia/files/NOTICIA DIARIO.pdf>. Acesso em: 10 out. 2019.

Diniz, J.; Cardoso, A. L.; Stahl, J. A.; Villetti, M. A.; Martins, A. F. Poder calorífico da casca de arroz, caroço de pêssego, serragem de eucalipto e de seus produtos de pirólise. Ciência e Natura, v. 26, n. 2, p. 25-32, 2004.

EMATER - Empresa de Assistência Técnica e Extensão Rural. Quinzena do pêssego tem início em Pelotas. Pelotas: EMATER, 2014. Disponível em: <http://www.emater.tche.br/site/noticias/detalhe-noticia.php?id=20480 . Acesso em: 02 abr. 2020.

Fachinello, J. C. Rastreabilidade em toda a cadeia dá mais segurança ao consumidor. Revista de Agronegócio da FGV, p. 38-40, set. 2004. Disponível em: $<$ http://bibliotecadigital.fgv.br/ojs/index.php/agroanalysis/article/download/51896/50 699>. Acesso em: 2 abr. 2020.

Heylmann, K. K. A. Produção, caracterização e aplicação de carvão ativado de caroço de pêssego no tratamento de efluente têxtil. Pelotas: Universidade Federal de Pelotas, 2015. (Trabalho de conclusão de curso).

Hueblin, H. J. Modelo para aplicação da metodologia Zeri: sistema de aproveitamento integral da biomassa de árvores de reflorestamento. Curitiba: CEFET-PR, 2001.

Madail, J. C. M.; Raseira, M. C. B. Aspectos da produção e mercado de pêssego no Brasil. Pelotas: EMBRAPA Clima Temperado, 2008. Disponível em: <https://ainfo.cnptia.embrapa.br/digital/bitstream/item/30929/1/Circular-80.pdf>. Acesso em: 2 abr. 2020.

Oliveira, M. P. Obtenção, caracterização e aplicações de carvão ativado a partir de caroços e pêssegos. Pelotas: Universidade Federal de Pelotas, 2008. (Tese de doutorado). 
Tashima, M. M.; Sousa, L. C.; Akasaki, J. L.; Silva, E. J.; Melges, J. L. P.; Bernabeu, J. J. P. Reaproveitamento de cinza de casca de arroz na construção civil. Holos Environment, v. 11, n. 1, p. 81-89, 2011. https://doi.org/10.14295/holos.v11i1.5435 (CC) Anformação da Licença: Este é um artigo Open Access distribuído sob os termos da Licença Creative Commons seja devidamente citada. 